\title{
Irish primary schools are in favour of the use of community nutrition assistants as a support for healthy school policy development
}

\author{
C. Johnston Molloy, S. Kleemann and C. Glennon Slattery \\ Community Nutrition \& Dietetic Service, Health Service Executive, Dublin Mid-Leinster, Marlinstown Office Park, \\ Mullingar, Co. Westmeath, Republic of Ireland
}

The process of planning, and implementation, of health-promoting activities in schools is fundamental to their success and sustainability $^{(1)}$. A pilot project of nutrition policy development in primary schools in the Midland region of Ireland noted that with direct dietetic on-site visits schools developed appropriate and sustainable nutrition policy (M Clancy and C Johnston, unpublished results). However, as the number of schools enrolled in the project grew, there were insufficient community dietitians available for on-site visits, and schools did not feel empowered to develop policy (M McKeon and C Johnston, unpublished results). It has been noted that community nutrition assistants lead to increased local community dietetic coverage ${ }^{(2)}$. The purpose of the present study was to determine the views of teachers and parents on community nutrition assistant visits to primary schools to facilitate healthy school policy.

A semi-structured telephone questionnaire was developed containing open and closed questions. Parents $(n 8)$ and teachers $(n 14)$ from eight primary schools that had previously taken part in a healthy school policy development project in the Midland region of Ireland were initially contacted by letter to inform them of the survey. This contact was followed by a telephone call, and use of the questionnaire, to determine their views on the use of community nutrition assistants in this capacity.

Eight of fourteen teachers $(57 \%)$ and four of eight parents $(50 \%)$ took part in the study. All participants surveyed believed that community nutrition assistants would be of benefit to their particular schools. When asked, participants felt that the community nutrition assistants would need extra skills, and outlined these skills as: good communication skills; up-to-date nutrition knowledge; information and knowledge on the needs of the schools.

When asked to make suggestions on how to prepare community nutrition assistants for school liaisons, various issues and ideas were highlighted. The Table shows participant suggestions on the main issues to be addressed in training community nutrition assistants for school policy development visits.

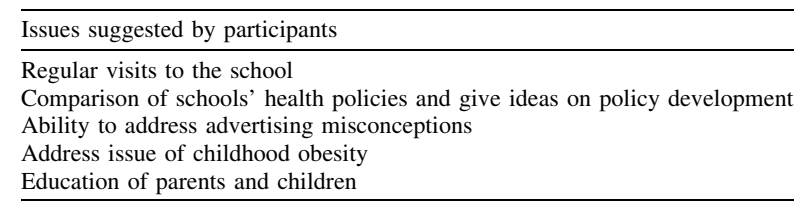

All participants in the study were in favour of the inclusion of community nutrition assistants in the roll out of a healthy schools policy development project. To progress with this initiative, it is essential that all issues raised are addressed as part of any future programme development and that community nutrition assistants are trained adequately for involvement in this process.

1. Rowling L \& Jeffreys V (2006) Health Educ Res 21, 705-718.

2. Kennedy LA, Ubido J, Elhassan S, Price A \& Sephton J (1999) J Hum Nutr Diet 12, 501-512. 